\title{
EVOLUTION OF POLYPHENOLS AND FLAVONOIDS LEVELS IN LEAVES, MESOCARP AND KERNEL OF THREE JUGLANS REGIA L. CULTIVARS
}

\author{
Ivona Mazilu ${ }^{1, *}$, Loredana Elena Vîjan ${ }^{2}$, Simona Giura ${ }^{3,4}$, Mihai Botu ${ }^{3,4}$ \\ ${ }^{1}$ Research Institute for Fruit Growing Pitesti, 402 Marului Street, Pitesti, Arges, RO 117450, Romania \\ ${ }^{2}$ University of Pitesti, Faculty of Sciences, Physical Education and Computer Science, \\ Department of Natural Sciences, 1 Targu din Vale Street, Pitesti, Arges, RO 110142, Romania \\ ${ }^{3}$ University of Craiova, Faculty of Horticulture, Department of Horticulture and Food Science, \\ 13 A.I. Cuza Street, Craiova, Dolj, RO 200585, Romania \\ ${ }^{4}$ University of Craiova - Fruit Growing Research and Extension Station (S.C.D.P.) Valcea, \\ 464 Calea lui Traian Street, Rm. Valcea, RO 240371, Romania
}

\begin{abstract}
This paper studies polyphenols and flavonoids level evolution in Juglans regia L. leaves and mesocarp during the growing season, as well as compounds evolution in the walnut kernel for fully mature picked nuts, stored for eight months at room temperature. Both compounds, polyphenols and flavonoids were significantly influenced by cultivar, harvest moment, and, respectively, by the storage time. The highest content of polyphenols was found in 'Jupânești' cultivar's leaves, 'Vina' cultivar's kernel, and 'Franquette' cv. mesocarp. Also, nut mesocarp and leaves samples harvested in July and nut kernel stored till next March contained maximum polyphenols levels. The highest flavonoid content was determined for 'Vina' cultivar's leaves, 'Franquette' cultivar's fruit mesocarp, 'Vina's kernel, leaves and mesocarp sampled in July and nut kernel stored until March. For the entire experiment, maximum polyphenols level was found in 'Jupânești' cultivar's leaves harvested in July. Flavonoids reached their highest level in case of 'Franquette' kernel stored until March. The three studied cultivars: 'Jupânești', 'Vina' and 'Franquette' can be valuable sources of phenolic compounds.
\end{abstract}

Keywords: polyphenols, flavonoids, Juglans regia L.

\section{INTRODUCTION}

The common walnut (Juglans regia L.), known also under the name of Carpathian, English or Persian walnut is an important nut crop mainly for its fruits that are sold in-shell or valorised as kernels. Walnut world production, according to FAO Database (2021), was harvested in 2019 from 1,305,349 ha of organized orchards and reached 4,498,442 t. According to same source, the main walnut production countries were in 2019: China (2521,504 t), USA $(592,390 \mathrm{t})$, Iran $(321,074 \mathrm{t})$, Turkey $(225,000 \mathrm{t})$, Ukraine $(125,850 \mathrm{t})$, Chile (122,950 t), Uzbekistan (50,660 t), Romania $(49,580 \mathrm{t})$, etc. Walnut trees are grown also for the high priced timber. After walnut harvesting and processing, the kernels are extracted and important quantities of shells result. Besides the walnut 
kernels, which can be eaten raw or processed, the young green fruits, leaves, green mesocarp, pollen, shells, etc. can be used for different purposes.

Walnut and by-products derived from the walnut tree contains flavonoids, phospholipids, sterols, triterpenes, quinones, oils, tannins, essential fatty acids (Amaral et al., 2004; Pereira et al., 2008; Cosmulescu et al., 2014; Kafkas et al., 2017).

Our previous studies described polyphenols, flavonoids, and tannins content in walnut leaves, green walnut husk and fruit during growing season (Bizera et al., 2019; Giura et al., 2019).

The present study followed the evolution of polyphenols and flavonoids levels in the leaves and fruits mesocarp from three walnut varieties ('Jupânești', 'Vina', and 'Franquette') depending on the sampling time (15 June, 6 July, 27 July, 17 August, and 7 September), as well as the variation of the two classes of compounds in the three cultivars, during the storage periods ( 8 months) in the kernel from walnut harvested at full maturity stage.

\section{MATERIALS AND METHODS \\ Plant material and sampling}

The walnut leaves and the green walnuts were collected from S.C.D.P. Vâlcea germplasm collection during summer of 2018 from three cultivars: one Romanian ('Jupânești'), one American ('Vina'), and one French cv. ('Franquette'). The walnut leaves and the green walnuts were sampled in early morning hours, and stored at $0-4{ }^{\circ} \mathrm{C}$ until their use. Before being analysed, the walnut leaves and the green walnuts were washed and wiped with a paper towel. Then, the walnut leaves and the fruits mesocarp cut into pieces and transformed into a homogeneous mixture with a vertical mixer.

The walnut fruits of three cultivars were collected during September and October 2018, depending on the cultivar harvesting time, from UCv-S.C.D.P. Vâlcea germplasm collection.

'Jupânești' walnut cultivar is one of the most propagated in Romania, it has been selected in a local population of walnuts from Argeș county and promoted as new cultivar in 1984 by Research Institute for Fruit Growing of Pitești - Mărăcineni. The cultivar is medium to high vigorous, precocious and productive, has mostly terminal bearing, the fruits are medium in size $(12.2 \mathrm{~g})$, kernel content is higher than $50 \%$. Flowering time is medium-late, the dichogamy is of protandrous type, harvesting time takes place first weeks of September.

'Vina' is a cultivar released by University of California, Davis (USA) in 1968 and obtained from a 'Franquette' x 'Payne' cross. It has been used extensively in the last decades in California for new plantings. The cultivar has medium-high vigor, is precocious and very productive, lateral bearer, the fruits are medium in size (11-12 g), kernel content varies from 49 to $51 \%$, harvesting time takes place end of September.

'Franquette' is an old French walnut cultivar, known for its very good kernel quality. The cultivar has been largely used in the past in Grenoble and Perigord areas of France, but also in other areas of the world, including California (USA). 'Franquette' trees are vigorous, they have terminal bearing, the fruits are medium (10-12 g) and kernel content goes up to $48 \%$. Flowering is late, of protandrous type and harvesting time takes place beginning of October (Achim et al., 2018).

After the harvest, samples were immediately dried and stored in the shell at room temperature until the start of the analysis. Bulk samples were selected randomly and the unwanted debrides were removed from bulk sample of walnut nuts. After the walnut fruits were cracked, the walnut kernel was stored at $5^{\circ} \mathrm{C}$ prior to experiment. At the analysis moment, the walnut kernel was transformed into a homogeneous mass using an electric grinding machine. 


\section{Chemical substances}

Gallic acid, catechin, and Folin-Ciocalteu reagent were purchased from Redox Bucharest - Sigma Aldrich, Dako, Epp. Romania. Ethanol, sodium hydroxide, sodium carbonate, sodium nitrite and aluminium chloride were purchased from Merck Romania SRL.

\section{Chemical analysis and equipment}

Quantitative determination of polyphenols and flavonoids was performed by spectrophotometric method using a UV-Vis spectrophotometer PerkinElmer Lambda25.

For determination of polyphenols from all samples, the methodology proposed by Singleton and Rossi (1965) was respected. The method principle is based on forming a blue coloured compound between phosphotungstic acid and polyphenols, in an alkaline medium. For analysis, an ethanolic extract of homogenised vegetal material with concentration $100 \mathrm{mg} / \mathrm{mL}$ was used.

The concentration of polyphenols was calculated using the calibration curve, performed under the same conditions as the sample, using the absorbance values at the maximum absorption, located at $765 \mathrm{~nm}$. In order to obtain the calibration curve, a stock solution of gallic acid was used. $0.5 \mathrm{~mL}$ of the ethanolic extract of vegetal material was added to a $10 \mathrm{~mL}$ flask containing $7 \mathrm{~mL}$ of distilled water and $0.5 \mathrm{~mL}$ of Folin-Ciocalteu reagent. After 5 minutes of rest, $2 \mathrm{~mL}$ solution of sodium carbonate $10 \%$ was added. After 60 minutes of rest, absorbance of the samples was measured and the concentration of polyphenols was estimated. Finally, the content of polyphenols was expressed as mg gallic acid (GAE) equivalent/ $100 \mathrm{~g}$ of vegetal material.

For determination of flavonoids from all samples, the methodology proposed by Zhishen et al. (1999) was respected. The method principle is based on the formation of a yellow-orange-coloured compound by the reaction of flavonoids and aluminium chloride. For analysis, an ethanolic extract of vegetal material with concentration $100 \mathrm{mg} / \mathrm{mL}$ was used.

The concentration of the flavonoids has been calculated using the calibration curve, performed under the same conditions as the sample solutions, using the absorbance values of the maximum absorption, located at $510 \mathrm{~nm}$. To obtain the calibration curve, a stock solution of catechin was made. $1 \mathrm{~mL}$ of ethanolic extract of vegetal material was added to a $10 \mathrm{~mL}$ volumetric flask containing $6 \mathrm{~mL}$ of distilled water and $0.5 \mathrm{~mL}$ of sodium nitrite $5 \%$. After 5 minutes of rest, in the volumetric flask was added $0.5 \mathrm{~mL}$ of aluminium chloride $10 \%$. After 5 minutes, $2 \mathrm{~mL}$ solution of sodium hydroxide $1 \mathrm{M}$ was added. The absorbance of the solution at $510 \mathrm{~nm}$ was measured. Flavonoids concentration was estimated using a calibration curve of catechin and, finally, the content of flavonoids was expressed as $\mathrm{mg}$ catechin equivalent/100 $\mathrm{g}$ of vegetal material

\section{RESULTS AND DISCUSSIONS \\ Leaves polyphenols level}

On average of the sampling moments in 2018 (Figure 1), the highest content of leaf polyphenols was determined in the 'Jupânești' cv. (7009.80 mg GAE/100 g FW), with 39.74\% higher compared to 'Franquette', but without significant difference compared to 'Vina' (6847.80 mg GAE/100 g FW). Regarding the interaction cultivar $\times$ sampling moment, the former trend was maintained in the first three sampling moments, so that on 17 August and 7 September 'Franquette' cv. has a higher level of polyphenols than 'Jupânești' (7643.00 mg GAE/100 g FW and $4247.00 \mathrm{mg} \mathrm{GAE} / 100 \mathrm{~g} \mathrm{FW}$, on 17 August; $4290.00 \mathrm{mg}$ GAE/100 g FW and $3416.00 \mathrm{mg}$ GAE/100 g FW, on 7 September). The maximum level of polyphenols was determined in the leaves of the 'Jupânești' cv., harvested on 27 July (10425.00 mg GAE/100 g FW), the lowest content being determined for the 'Franquette' cv., on 15 June (2510.00 mg GAE equivalent/ $100 \mathrm{~g} \mathrm{FW).}$ 


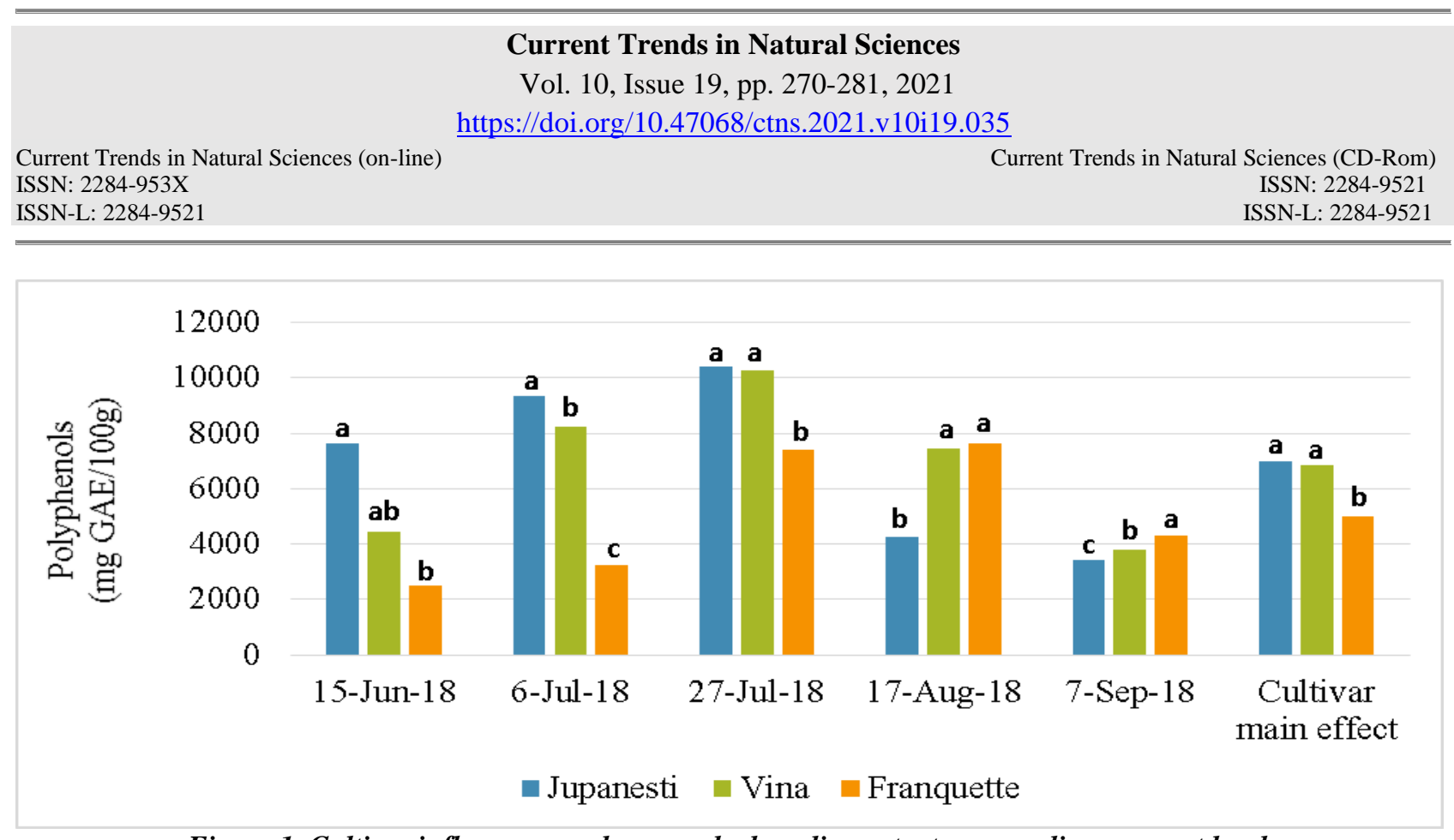

Figure 1. Cultivar influence over leaves polyphenolic content on sampling moment levels

As shown in Figure 2, on the average of the cultivars, 27 July represents the moment of maximum accumulation of polyphenols (9370.00 mg GAE/100 g), and 7 September, is characterized by an insignificant reduction below the level of 15 June (3834.33 mg GAE/100 g FW).

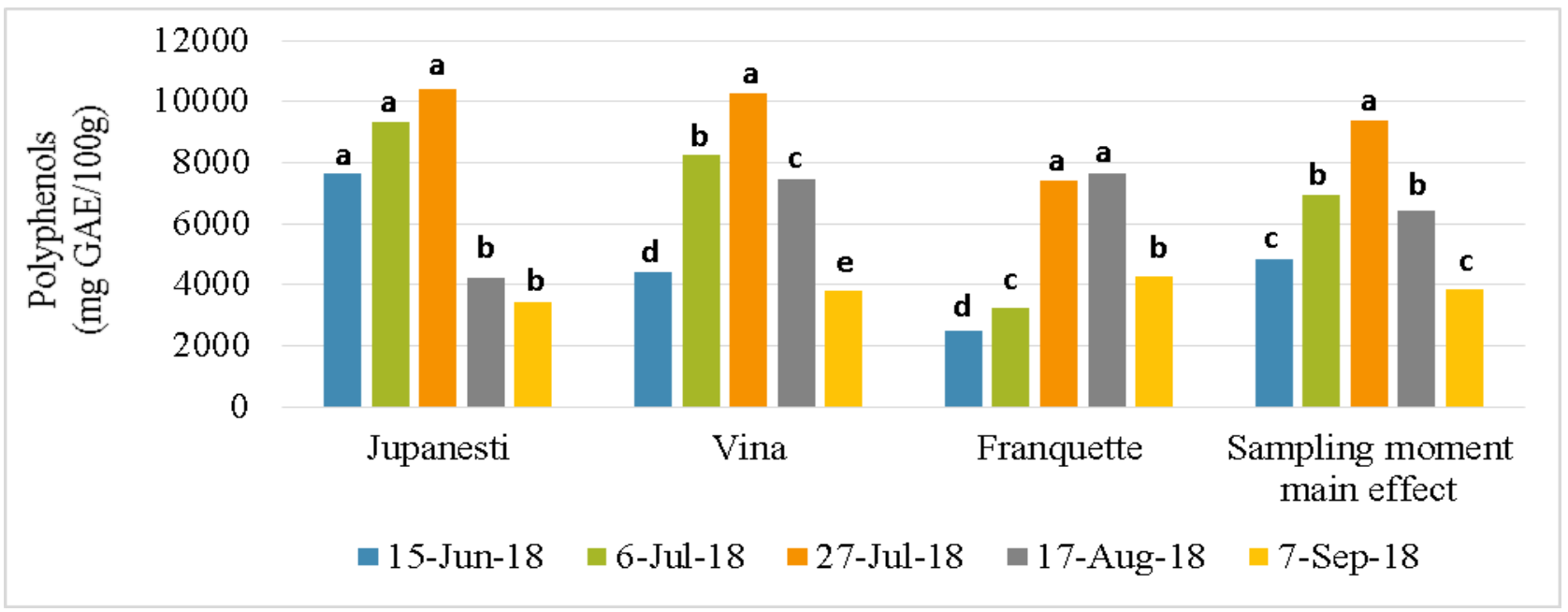

Figure 2. Sampling moment influence over leaves polyphenolic content on cultivar level

The polyphenols level increases insignificantly in the 'Jupânești' leaves between 15 June and 6 July (by $36.60 \%$, up to a maximum of $10425 \mathrm{mg} \mathrm{GAE} / 100 \mathrm{~g} \mathrm{FW}$ ), and then decreases by $59.26 \%$ in August (below the level from 15 June). A significant upward trend is followed by 'Vina', with a maximum level of polyphenols in July (10286.00 GAE/100 g FW) and a significant reduction thereafter. Unlike 'Jupânești' and 'Vina', 'Franquette' (the phenological phases are delayed with 6-12 days compared to the other two cultivars) accumulates polyphenols until 17 August $(204.50 \%$, respectively up to $7643.00 \mathrm{mg}$ GAE/100 $\mathrm{g} \mathrm{FW}$ ), followed by a decrease to $4290.00 \mathrm{GAE} / 100 \mathrm{~g} \mathrm{FW}$ on 7 September (significantly higher than the level determined on 15 June). 
Current Trends in Natural Sciences

Vol. 10, Issue 19, pp. 270-281, 2021

https://doi.org/10.47068/ctns.2021.v10i19.035

Current Trends in Natural Sciences (on-line)

ISSN: 2284-953X

Current Trends in Natural Sciences (CD-Rom)

ISSN: 2284-9521

ISSN-L: 2284-9521

ISSN-L: 2284-9521

\section{Leaves flavonoids level}

At the mean level of the sampling time factor, the highest flavonoid leaves level was determined for the 'Vina' cv. (Figure 3), $368.80 \mathrm{mg}$ catechin/100 g FW, with $15.40 \%$ and $46.70 \%$ higher than 'Jupânești' and, respectively, 'Franquette'. With one insignificant exception on 7 September, 'Vina' maintains a higher level of flavonoids during the experiment, reaching the maximum threshold of $466.00 \mathrm{mg}$ catechin/100 g FW on 27 July. 'Jupânești' had a higher level of flavonoids than 'Franquette', except on June 15, when it registered the minimum threshold of leaf flavonoids between the three varieties, $187.00 \mathrm{mg}$ catechin/100 $\mathrm{g} \mathrm{FW}$.

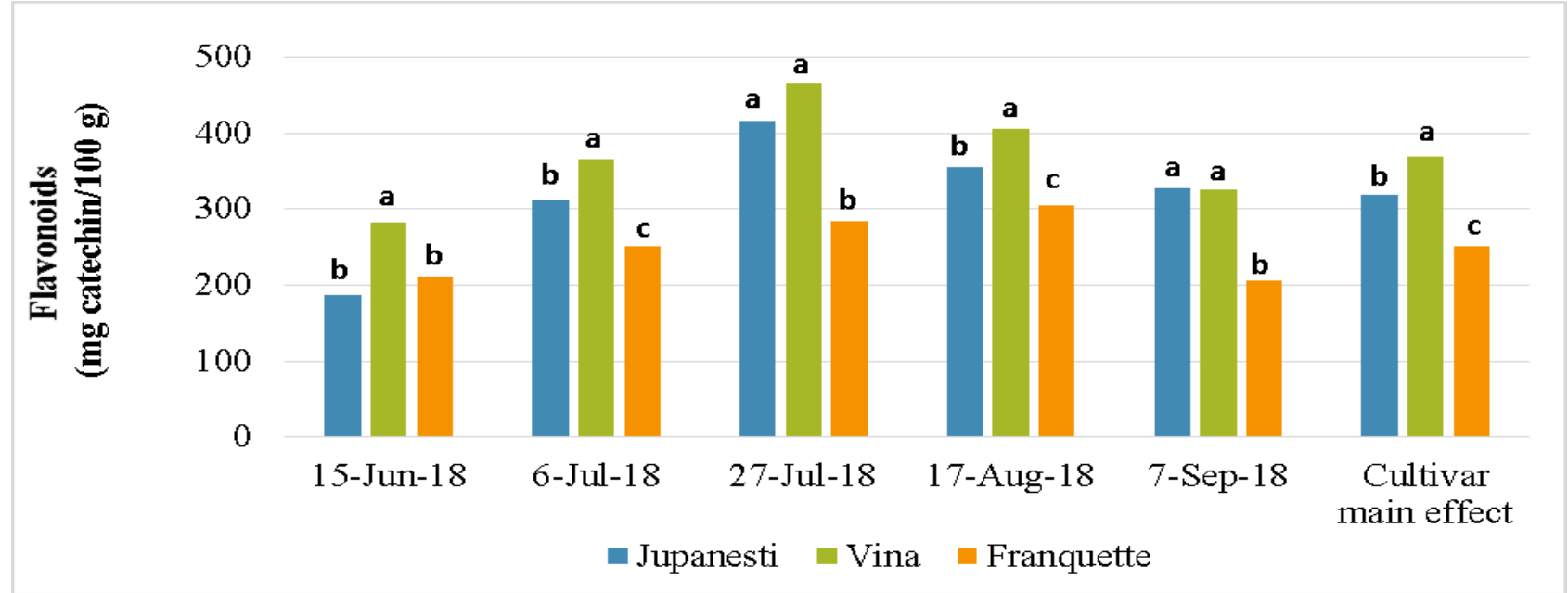

Figure 3. Cultivar influence over leaves flavonoid content on sampling moment levels

On the average level of the cultivar factor, 27 July represents the period of maximum accumulation of flavonoids ( $388.67 \mathrm{mg}$ catechin equivalent/100 g FW), and on 7 September, unlike polyphenols, the level of flavonoids is significantly higher than on 15 June $(286.00 \mathrm{mg}$ catechin equivalent/100 $\mathrm{g}$ FW versus $226.67 \mathrm{mg}$ catechin equivalent/100 g FW) (Figure 4).

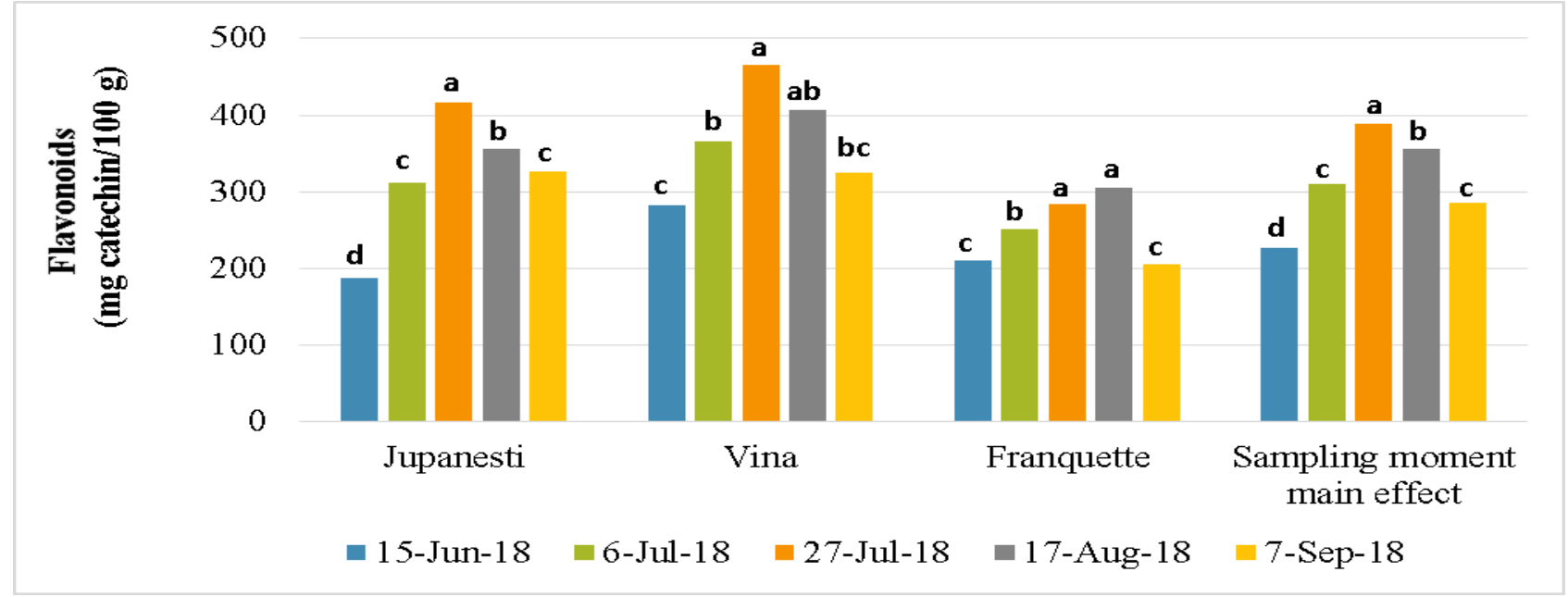

Figure 4. Sampling moment influence over leaves flavonoid content on cultivar levels 
'Vina' accumulates significant flavonoids by July (466.60 mg catechin/100 g FW, an increase of $65.26 \%)$, then registering a significant decrease until September (325.00 mg catechin/100 g FW, by 30.26\%). Similarly, 'Jupânești' reached its maximum flavonoids on July 27 (416.00 mg catechin/ $100 \mathrm{~g} \mathrm{FW}$ ) and subsequently lost $21.39 \%$ of its flavonoids on September 7. Except for June 15, 'Franquette' was characterized by the lowest flavonoid content, on average $31.83 \%$ lower than 'Vina'.

Malmir (2014) states that the presence of polyphenols in leaves is the result of a mechanism that allows plants to adapt to terrestrial habitats. In his experiment, the level of polyphenols was at its peak in mid-June (1860 mg GAE/100 g FW). The levels of polyphenols and flavonoids in the leaves are the result of the balance between biosynthesis and catabolism. In early leaf development, walnut leaf polyphenols is the main sink for phenylalanine and can be highly influenced by water content. As the leaf moves from the growth stage to the maturation stage, the polyphenols level decreases. This may be due to the transformation of soluble phenolic into insoluble cell-wall-bound constituents polyphenol into the lignification process. In Malmir (2014) study, the lowest level of flavonoids was detected in the early harvest (1780 mg quercetin/100 g FW), whereas the content was gradually increased during the leaf development (3230 mg quercetin/100 g FW).

Ebrahimi et al. (2018) și Jalili et al. (2012) found the highest content of phenolics compounds in walnut leaves in May and July. Amaral et al. (2008) determined two moments of polyphenols and flavonoids accumulation in walnut leaves, namely May and, similar to our study, June. The maximum level of polyphenols was reached by the 'Lara' cv., at the sampling in May. The level of these compounds decreases from May to June, increases in July, and decreases again in September. The authors state that the reduction in June is related to the rapid development of the fruit in June when most of the nutrients and photoassimilates are employed for fruit growth. It also explains the increase in flavonoid levels in July as related to sun exposure, because of their function as sun filters, which may explain their rise in July, since this was the month with a higher value of solar radiation.

\section{Mesocarp polyphenols level}

On average of the sampling moments, in the fruit mesocarp, the maximum polyphenols level was determined for the 'Franquette' cv. (3719.8 mg GAE/100 g FW, Figure 5), with 23.25\% and, respectively, $47.03 \%$ higher than the 'Jupânești' and 'Vina'.

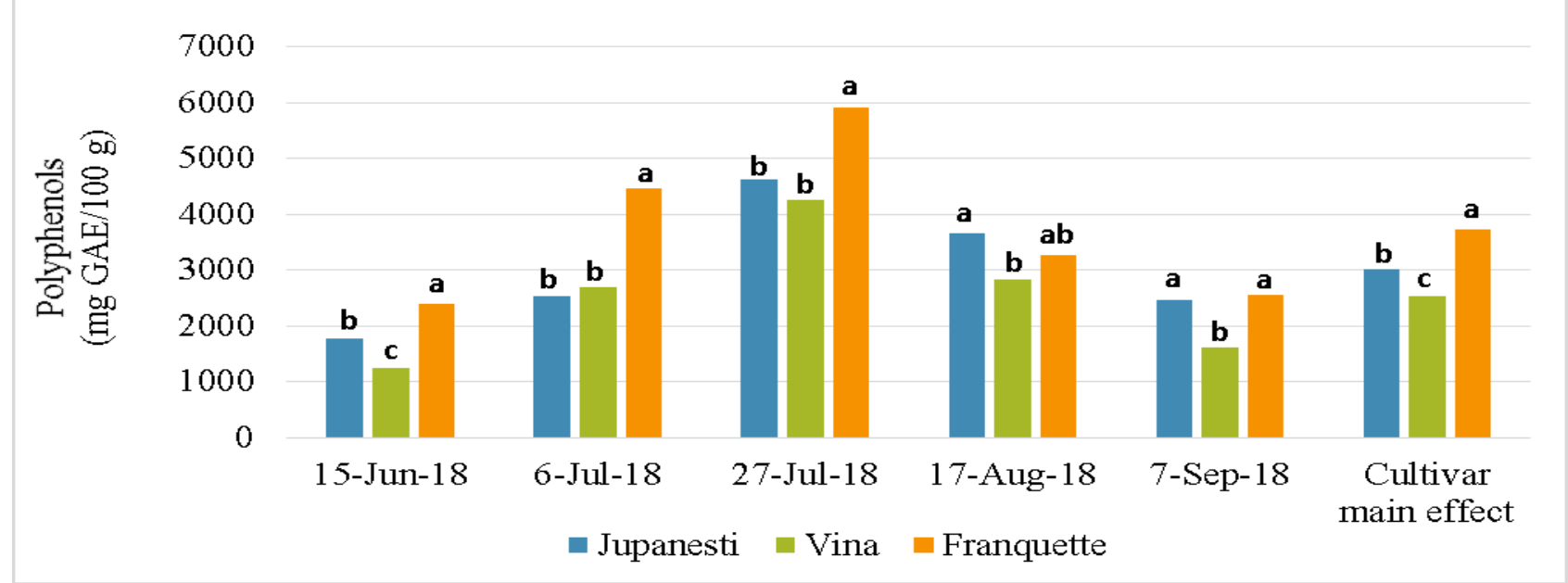

Figure 5. Cultivar influence over mesocarp polyphenolic content on sampling moment levels 
Except for 17 August, 'Jupânești' had a lower polyphenol content than 'Franquette' for the entire duration of the experiment. The maximum level of polyphenols in the mesocarp was determined for the 'Franquette' variety, on $27 \mathrm{July}, 5919.00 \mathrm{mg}$ GAE/100 g FW, the lower limit (1250.00 mg GAE/100 $\mathrm{g} \mathrm{FW}$ ) being reached by the 'Vina' variety, at the first sampling time (15 June).

On the average of the cultivar factor, the optimal moment of polyphenols accumulation in the mesocarp is 27 July (Figure 6), with an increase of $171.74 \%$ compared to 15 June (4932 mg GAE/ $100 \mathrm{~g} \mathrm{FW}$ ). Although there is a significant reduction in the level of polyphenols, in September the average value of polyphenol content is above the value of 15 June $(2213.67 \mathrm{mg} \mathrm{GAE} / 100 \mathrm{~g} \mathrm{FW}$ compared to $1815.00 \mathrm{mg} \mathrm{GAE} / 100 \mathrm{~g} \mathrm{FW}$ ).

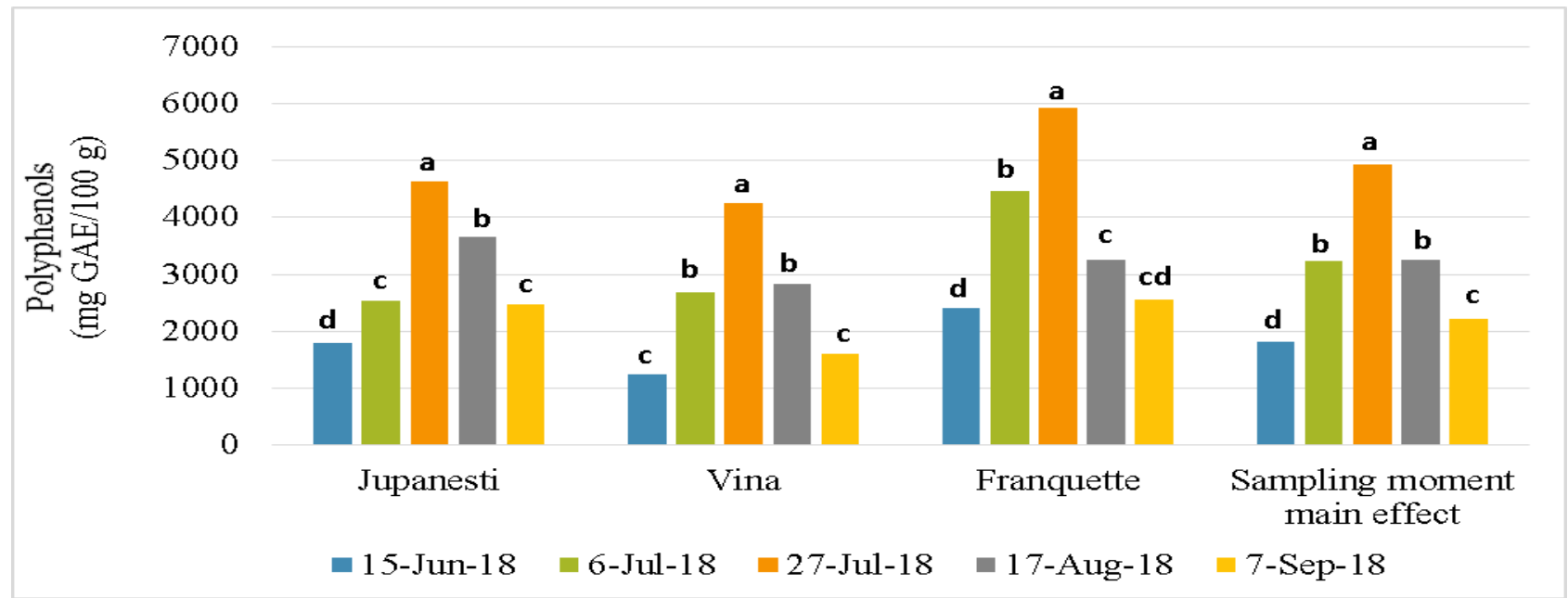

Figure 6. Sampling moment influence over mesocarp polyphenolic content on cultivar levels

For each of the studied cultivars, the level of mesocarp polyphenols increased on 27 July and decreased on 7 September to higher values compared to 15 June.

\section{Mesocarp flavonoids level}

For the entire period of the experiment, the 'Franquette' cv. was distinguished by a higher content of flavonoids in the mesocarp, $106.60 \mathrm{mg}$ catechin/100 g FW, 31.33\% higher compared to 'Jupânești' (Figure 7), but without significant differences from 'Vina'.

The highest flavonoid level in this structure was determined in the 'Franquette' cv., in the sample of 17 August (149.00 mg catechin/100 g FW), while the lowest level was showed by the 'Jupânești ' cv., on 7 September (32.00 mg catechin/100 g FW).

Considering together the 3 cultivars, as shown in Figure 8 , the maximum accumulation of flavonoids was recorded in 27 July ( $121.67 \mathrm{mg}$ catechin/100 g FW), exceeding by $70.57 \%$ value from 15 June $(71.33 \mathrm{mg}$ catechin/100 $\mathrm{g} \mathrm{FW})$. The level of flavonoids, determined at the end of the experiment, was insignificantly lower than on 15 June $(67.33 \mathrm{mg}$ catechin/100 $\mathrm{g}$ FW compared to $71.33 \mathrm{mg}$ catechin/100 g FW). 


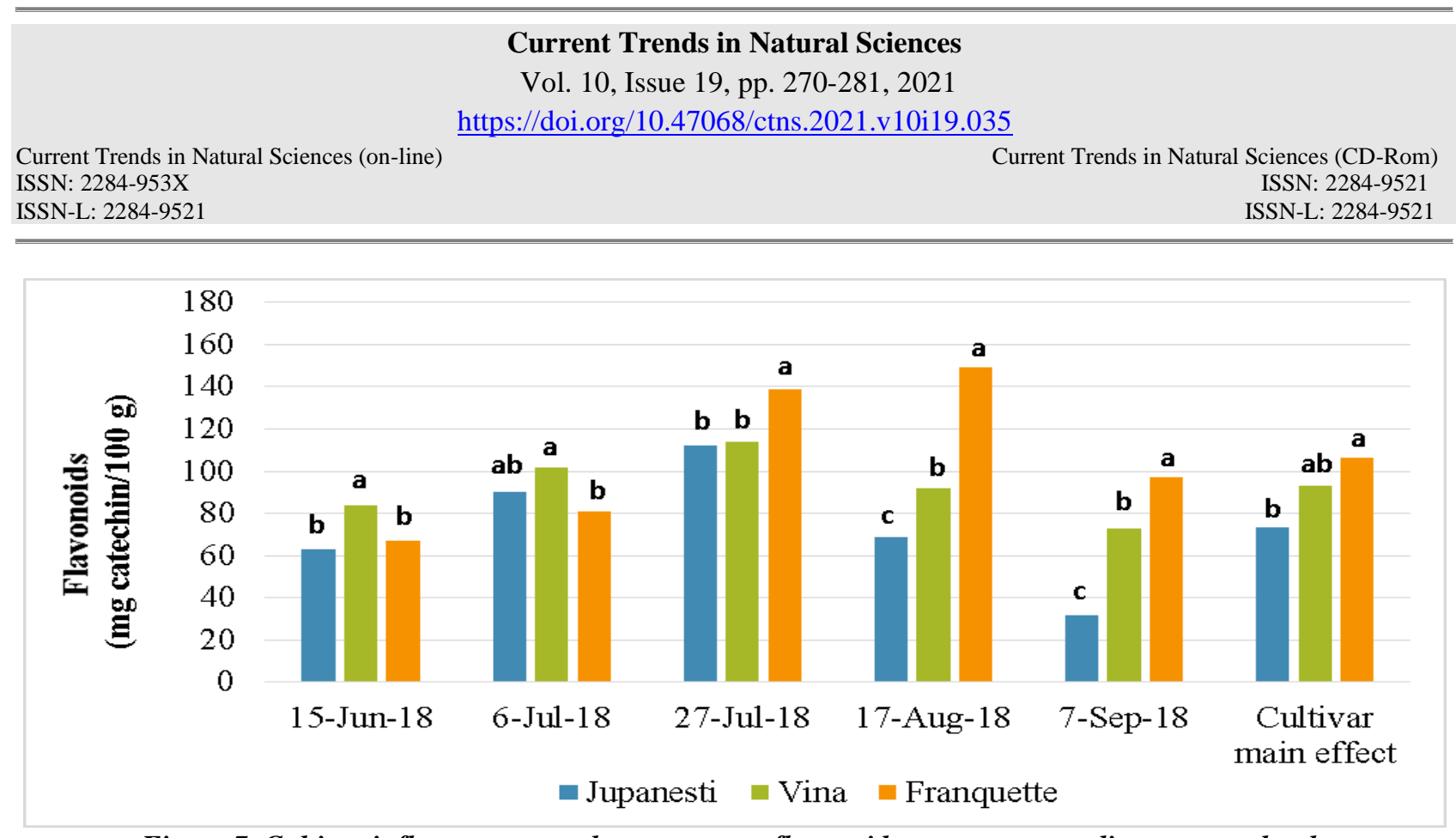

Figure 7. Cultivar influence over walnut mesocarp flavonoid content on sampling moment levels

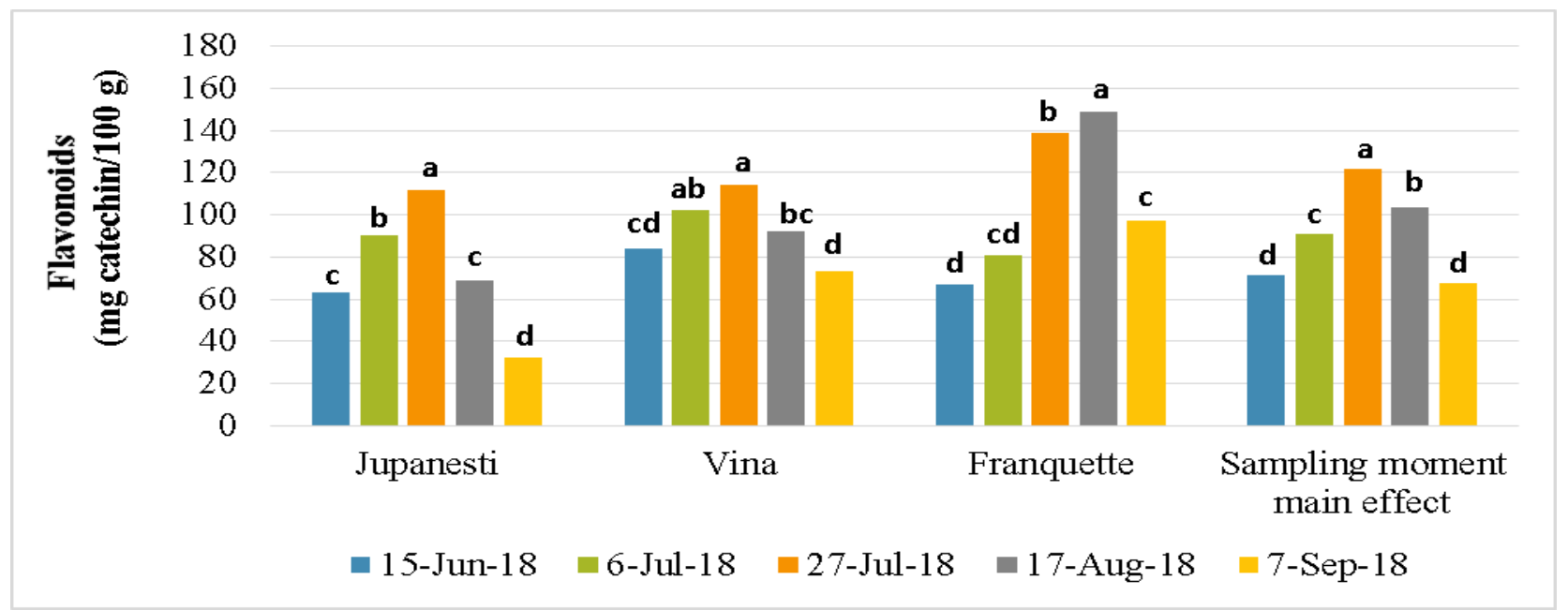

Figure 8. Sampling moment influence over walnut mesocarp flavonoid content on cultivar levels

'Vina' and 'Jupânești' varieties accumulated the maximum level of flavonoids in the mesocarp on 27 July (112.00 mg catechin/100 g FW and $114.00 \mathrm{mg}$ catechin/100 g FW) and, until 7 September, reached a lower level compared to 15 June. 'Franquette' accumulated a maximum level of flavonoids in August (149.00 mg catechin/100 g FW), $122.38 \%$ higher than on 15 June, and by September recorded a loss of flavonoids of $34.90 \%$, reaching $97 \mathrm{mg}$ catechin/100 $\mathrm{g} \mathrm{FW}$, higher than the 15 June level.

Soto-Madrid et al. (2021) state that walnut green husk is a rich polyphenols source and its biological activity could be dependent on the ripeness stage of the raw material. Similarly, Jakopic et al. (2007) observed the existence of a close interaction between cultivar and sampling data for most of the phenolics analyzed. Like in our study, however, except syringic acid, the content levels of the main phenolic compounds under investigation were highest in 'Franquette' but at the end of June.

Wianowska et al. (2016) investigated the phenolic content of walnut green husks from different cultivars and seedlings and found that the concentration of phenols at harvest was in the range of 
9064 - $11770.7 \mathrm{mg}$ GAE/100 g FW, which represents higher values than those obtained in the present study.

Similar to our study, according to Wianowska et al. (2016), the flavonoid content of walnuts ranges from $28.00 \mathrm{mg}$ quercetin/100 g FW to $257.00 \mathrm{mg}$ quercetin/100 g FW depending on the cultivar. Still, there were differences concerning the sampling moments: the highest concentration of flavonoids was found in the 'Champion' green husks harvested on 5 May (415.00 mg quercetin/ $100 \mathrm{~g}$ FW), whereas the 'Rasna' green husks harvested on 5 September were found to have the lowest concentration of flavonoids (47.00 mg quercetin/100 g FW).

\section{Kernel polyphenols level}

For the whole experiment, the polyphenols content determined in the walnut kernel was higher for 'Vina' (2529.17 mg GAE/100 g FW), by $4.9 \%$ compared with 'Franquette' and by $62.42 \%$ compared with 'Jupânești' (Figure 9). It reached its maximum in the 'Vina' cv. on 11 March 2019 (4600.00 mg GAE/100 g FW), and it was significantly reduced by $88.19 \%$ on the last determination (20 June 2019). The lowest polyphenol content was determined in the 'Jupânești' walnut kernel stored until 20 June 2019 (340.67 mg GAE/100 g FW).

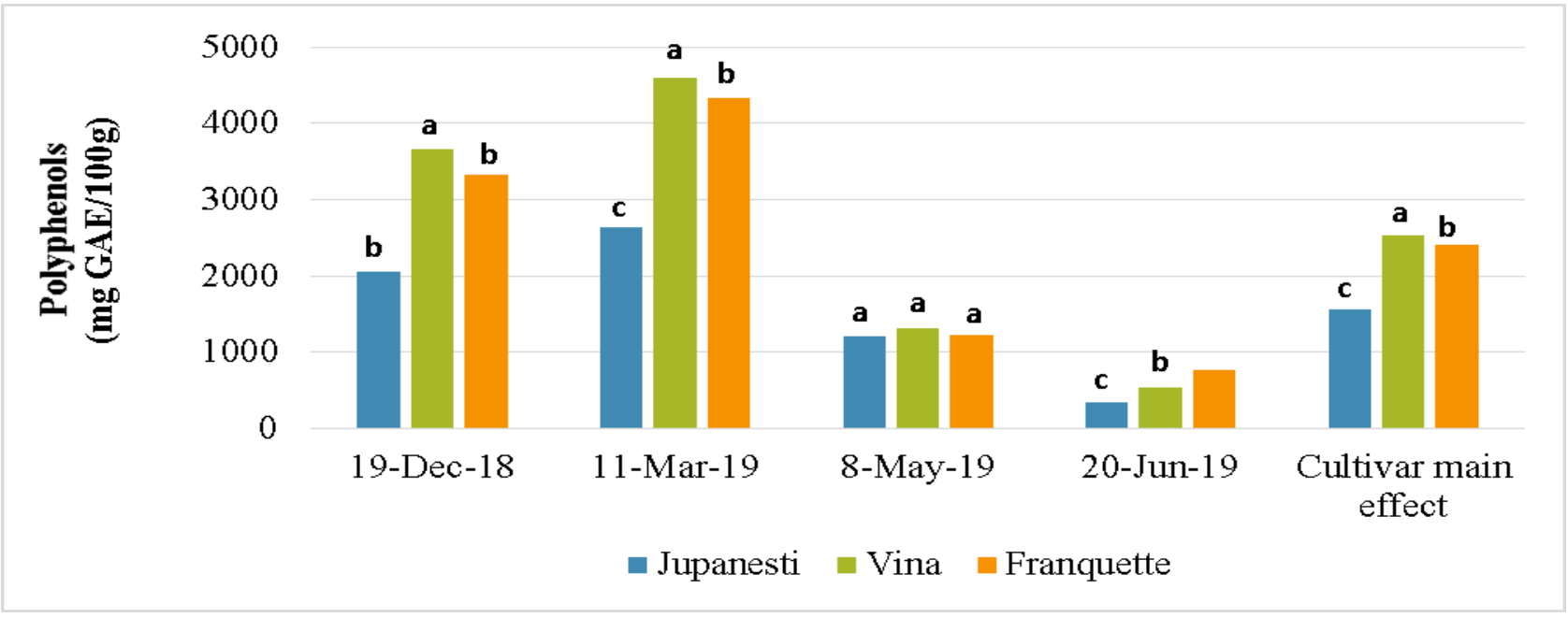

Figure 9. Cultivar influence over walnut kernel polyphenols content on storage time levels

As Figure 10 presents, on average, on 11 March 2019, the concentration of polyphenols reached its maximum in the walnut kernel (with an average of $3857.67 \mathrm{mg}$ GAE/100 $\mathrm{g} \mathrm{FW}$ ), decreasing without exception until 20 June 2019 (550.44 mg GAE/100 g FW), on average by 85.73\% compared to 11 March and by $81.73 \%$ compared to 19 December 2018. 


\section{Current Trends in Natural Sciences}

Vol. 10, Issue 19, pp. 270-281, 2021

https://doi.org/10.47068/ctns.2021.v10i19.035

Current Trends in Natural Sciences (on-line)

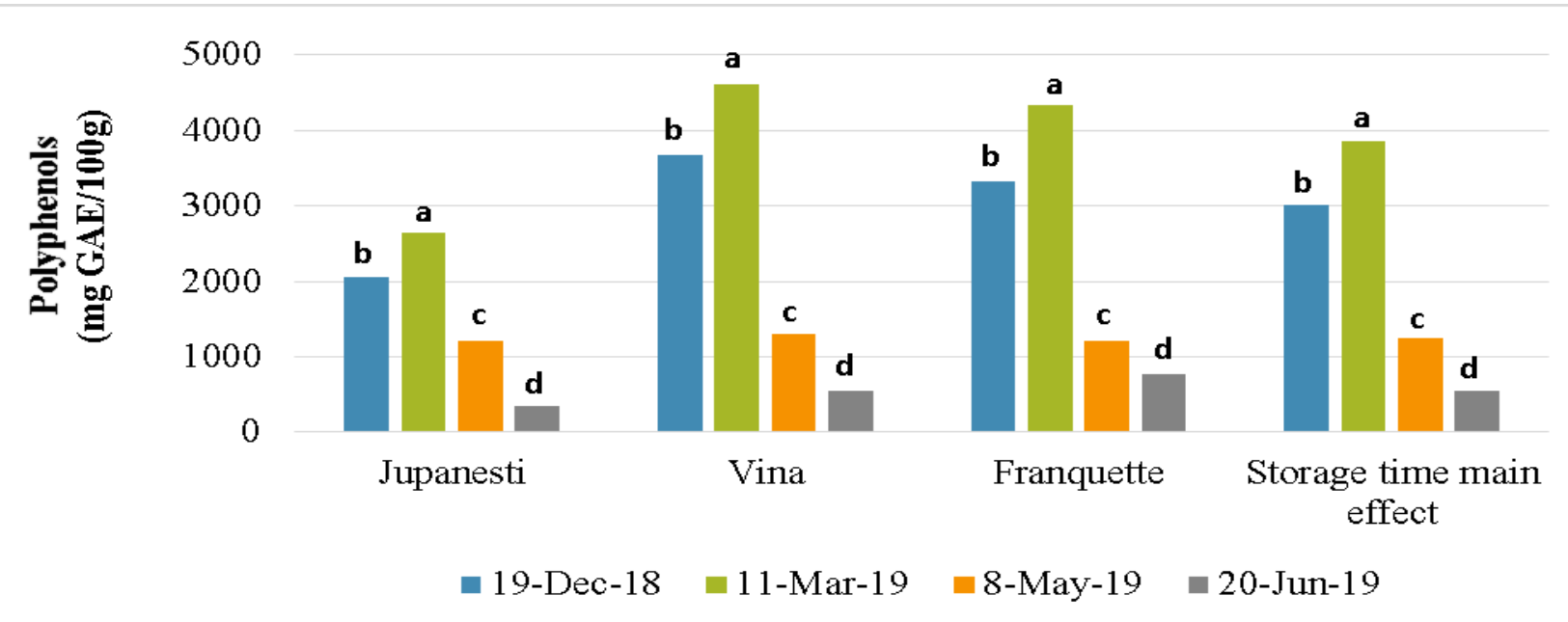

Figure 10. Storage time influence over walnut kernel polyphenols content on cultivar levels

\section{Kernel flavonoids level}

Similarly, at the average of the storage time, flavonoids had a higher concentration in the 'Vina' variety (437.92 $\mathrm{mg}$ catechin/100 $\mathrm{g} \mathrm{FW}$ ), with $4.41 \%$ compared to 'Franquette' and 29.43\% compared to 'Jupânești' (Figure 11). The maximum level of flavonoids in the kernel was determined for 'Franquette', on 11 March 2019 (896.33 mg catechin/100 g FW), and the lowest limit was reached on 20 June 2019 by 'Jupânești ' (93.33 mg catechin/100 g FW).

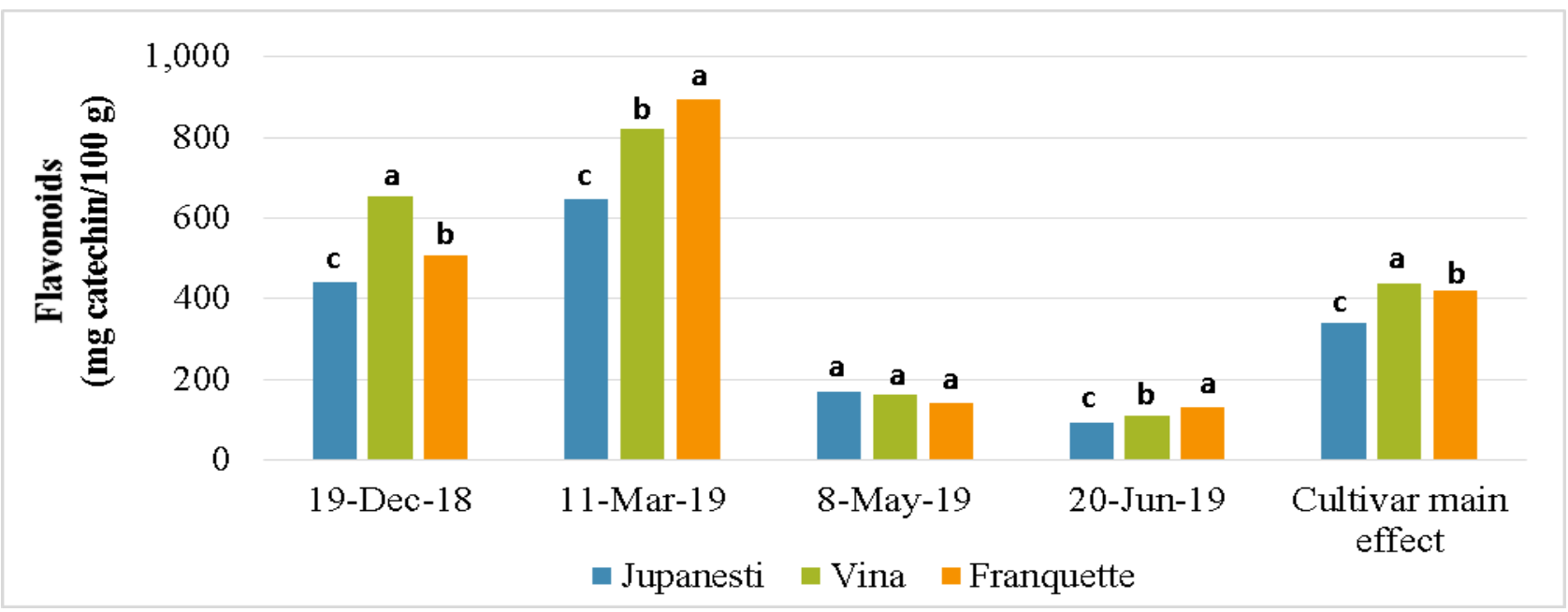

Figure 11. Cultivar influence over walnut kernel flavonoid content on storage time levels

All 3 cultivars showed an increasing trend in flavonoid content on 11 March 2019 (at an average value of $788.89 \mathrm{mg}$ catechin/100 g FW, see Figure 12), followed by a significant, fast depreciation (to an average value of $111.67 \mathrm{mg}$ catechin/100 g FW on 20 June 2019). 


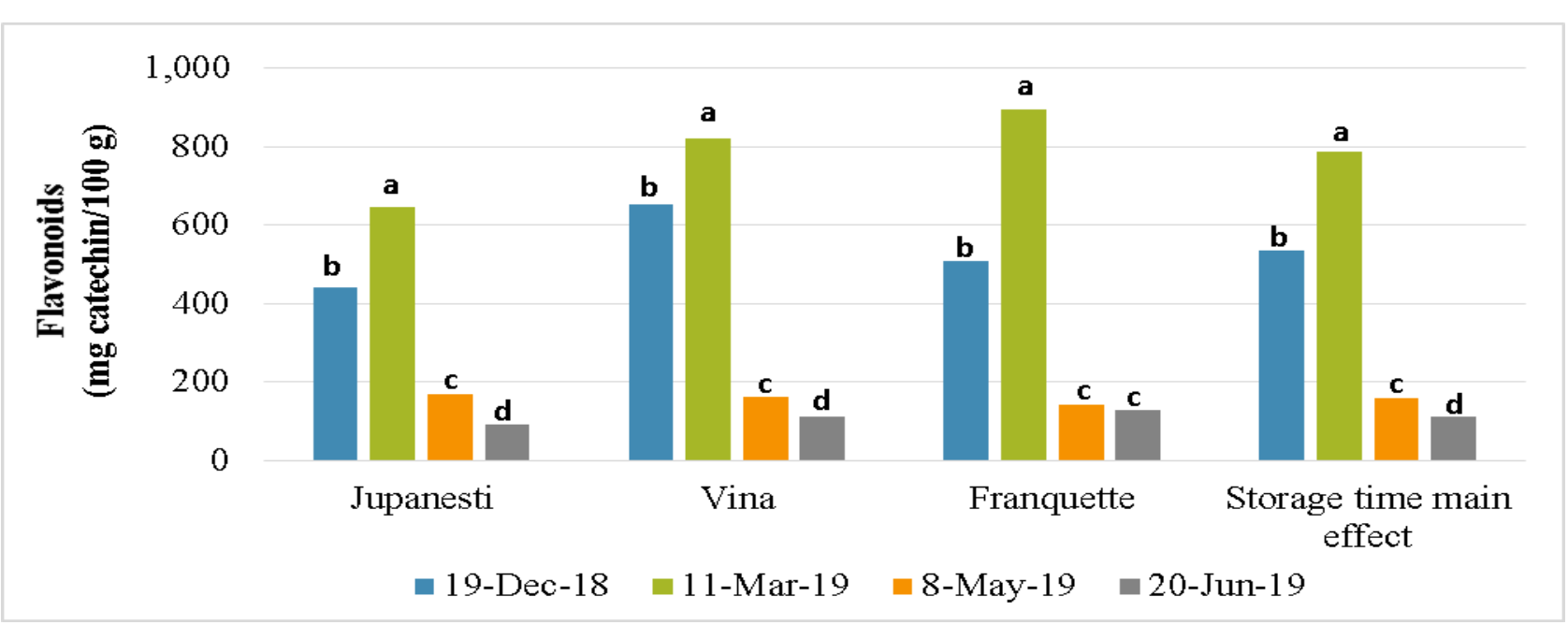

Figure 12. Storage time influence over walnut kernel flavonoid content on cultivar levels

According to Ebrahimi et al. (2018), antioxidant components in Persian walnut kernel virtually belong to phenolic component and there are very low amounts of flavonoids and iso-flavonoids in this nut. Also, other parts of this fruit that are not edible such as husk, hull, shell, and leaves have a high amount of flavonoid components. Still, in our study, mean flavonoids levels in walnut kernel exceeded those of leaves and green husk (398.56 versus 313.27 and $90.93 \mathrm{mg}$ catechin/100 g FW).

Christopoulos et al. (2011) found that after 12 months, the greatest losses of total polyphenols occurred in kernels stored at $20^{\circ} \mathrm{C}$ under air (averaging approximately $48 \%$ ), which represent a lower decrease than we found.

Nevertheless, walnut kernel remains an important phenolic source. As Abe et al. (2010) stated the phenol compound levels in nuts are influenced by environmental factors, soil composition, and maturation level. The authors also studied the polyphenolic content in 11 nuts species and found that walnuts were the richest (with $2499 \pm 94 \mathrm{mg} \mathrm{GAE} / 100 \mathrm{~g} \mathrm{FW})$, followed by pecan $(703 \pm 44 \mathrm{mg}$ GAE/100 g FW) and peanuts (597 $\pm 6 \mathrm{mg} \mathrm{GAE} / 100 \mathrm{~g} \mathrm{FW})$, while the lowest polyphenolics level was found in dehydrated macadamia nuts $(87 \pm 2 \mathrm{mg} \mathrm{GAE} / 100 \mathrm{~g} \mathrm{FW})$.

\section{CONCLUSION}

Both compound classes, polyphenols, and flavonoids were significantly influenced by cultivar, leaves, and nuts sampling moment, and, respectively, by the nuts storage time. The highest mean content of polyphenols was found in leaves, in 'Jupânești ' cultivar (7009.80 mg GAE/100 g FW), in mesocarp, in 'Franquette' cv. (3719.80 mg GAE/100 g FW), and in kernel, in 'Vina' (2529.17 mg GAE/100 g FW). Also, leaves and nut mesocarp samples harvested on 27 July 2018 and nut kernel stored till next March contained the highest mean polyphenols levels (9370.00, 4932.00, and $3857.67 \mathrm{mg} \mathrm{GAE} / 100 \mathrm{~g} \mathrm{FW}$ ).

The highest mean flavonoid content was determined in leaves of 'Vina' cultivar $(368.80 \mathrm{mg}$ catechin/100 g FW), in mesocarp from 'Franquette' (106.60 mg catechin/100 g FW), on 27 July 2018 sampled leaves and mesocarp (388.67 and $121.67 \mathrm{mg}$ catechin/100 g FW ) and nut kernel stored until next March (788.89 mg catechin/100 g FW). 
For the entire experiment, maximum polyphenols level was found in 'Jupânești' cultivar's leaves harvested in 27 July 2018. Flavonoids reached their maximum level in the 'Franquette' kernel stored until 11 March 2019.

As our data confirm, the three studied cultivars: 'Jupânești', 'Vina', and 'Franquette' can be valuable sources of phenolic compounds.

\section{REFERENCES}

Abe, L. T., Lajolo, F. M., Genovese, M. I. (2010). Comparison of Phenol Content and Antioxidant Capacity of Nuts. Food Science and Technology, 30, 254-259.

Achim, G., Baciu, A., Botu, I., Botu, M., Cosmulescu, S., Glăman, G., Godeanu, I. (2018). Cultura nucului [Walnut culture]. Editura Alma, Craiova 59-66.

Amaral, J.S., Seabra, R.M., Andrade, P.B., Valentão, P., Pereira, J.A., Ferreres, F. (2004). Phenolic Profile in the Quality Control of Walnut (Juglans regia L.) Leaves. Food Chemistry, 88(3), 373-379.

Amaral, J. S., Valentão, P., Andrade, P. B., Martins, R. C., Seabra, R. M. (2008). Do Cultivar, Geographical Location and Crop Season Influence Phenolic Profile of Walnut Leaves? Molecules, 13(6), 1321-1332.

Bizera, M., Giura, S., Scutelnicu, A., Preda, S., Botu, M., Vijan, L. E. (2019). Physico-Chemical Characterization of some Walnut Fruits Collected in 2018 from University of Craiova - S.C.D.P. Vâlcea, România. Current Trends in Natural Sciences, 8(15), 169-178.

Christopoulos, M. V., Tsantili, E. (2011). Effects of Temperature and Packaging Atmosphere on Total Antioxidants and Colour of Walnut (Juglans regia L.) Kernels during Storage. Scientia Horticulturae, 131, 49-57.

Cosmulescu, S., Botu, M., Achim, G., Baciu, A., Gruia, M., Trandafir, I. (2014). Polyphenol Content in Walnut (Juglans regia L.) Mature Leaves. Acta Horticulturae, 1050, 205-212.

Ebrahimi, S., Jamei, R., Nojoomi, F., Zamanian, Z. (2018). Persian Walnut Composition and its Importance in Human Health. Int. J. Enteric Pathog, 6, 3-9.

Giura, S., Botu, M., Vulpe, M., Vîjan, L. E., Mitrea, R. (2019). Evolution of Polyphenols, Flavonoids, and Tannins Content in Walnut Leaves and Green Walnut Husk during Growing Season. Not Bot Horti Agrobo, 47(4), 12641271.

Jakopic, J., Colaric, M., Veberic, R., Hudina, M., Solar, A., Stampar, F. (2007). How Much do Cultivar and Preparation Time Influence on Phenolics Content in Walnut Liqueur? Food Chemistry, 104(1), 100-105.

Kafkas, E., Burguta, Ozcan, H., Ozcan, A., Sutyemez, M., Kafkas, S., Türemis, N. (2017). Fatty Acid, Total Phenol and Tocopherol Profiles of some Walnut Cultivars: A Comparative Study. Food And Nutrition Sciences, 8(12), 10741084.

Jalili A, Sadeghzade A. (2012). Comparative Phenolic Profile of Persian Walnut (Juglans regia L.) Leaves Cultivars Grown in Iran. Afr J Biochem Res., 6(3), 33-38.

Malmir, H. A. (2014). The Changes in Phenolic and Flavonoids Compound Related to the Harvest Times and Enzyme Activity during Stages of Leaves Development in Juglans regia L. International Journal of Agriculture and Forestry, 4(4), 338-342.

Pereira, J.A., Oliveira, I., Sousa, A., Ferreira, I.C.F.R., Bento, A., Estevinho, L. (2008). Bioactive Properties and Chemical Composition of Six Walnut (Juglans regia L.) Cultivars. Food and Chemical Toxicology, 46(6), 21032111.

Singleton, V.L., Rossi, J.A.Jr. (1965). Colorimetry of Total Phenolics with Phosphomolybdicphospho-tungstic acid Reagents. American Journal of Enology and Viticulture 16(3), 144-158.

Soto-Madrid, D., Gutiérrez-Cutiño, M., Pozo-Martínez, J., Zúñiga-López, M. C., Olea-Azar, C., Matiacevich, S. (2021). Dependence of the Ripeness Stage on the Antioxidant and Antimicrobial Properties of Walnut (Juglans regia L.) Green Husk Extracts from Industrial By-Products. Molecules, 26(10), 2878.

Zhishen, J., Mengcjheng, T., Jianming, W. (1999). The Determination of Flavonoid Contents in Mulberry and their Scavenging Effects on Superoxide Radicals. Food Chemistry 64(4), 555-559.

Wianowska D., Garbaczewska S., Cieniecka-Roslonkiewicz A., Dawidowicz A.L., Jankowska A. (2016): Comparison of Antifungal Activity of Extracts from Different Juglans Regia Cultivars and Juglone. Microb Pathog, 100: 263-267.

FAO Stat Database Web Page, 2021. http://www.fao.org/faostat/en/\#data/QC 